\title{
DIAGNOSTIC TECHNIQUES IN AID OF SENTENCING
}

\author{
Ralph Brancale*
}

I

INTRODUCTION

To curb the impulses of the "normal" person who may be inclined to indulge in antisocial behavior, the law has created certain restraints in the form of penal sanctions. Their underlying rationale reflects the hopeful conviction that punishment not only will directly exert a beneficially conditioning effect upon offenders, but will also serve both as a deterrent to others and as a retributory mechanism for satisfying the demands of the lex talionis.

It is obvious, however, at least to some extent, that these theories have not worked out in practice. Indeed, the history of penology is replete with evidence of failures to conduce desired behavior through punitive formulae. It need only be noted, by way of example, that the capital punishment meted out to pickpockets several centuries ago did not appreciably reduce the incidence of this type of crime. Enlightened penologists, who are probably in the minority, attribute this deficiency to the fact that insufficient account has generally been taken of the distinctive elements in the mental process of the individual criminal. Instead, undue emphasis seems to have been placed on retribution, which, in turn, stems from a basic, almost constitutional need of man to express his own aggression toward one who has behaved as he himself may have wished to. And since this mechanism is not consciously perceived, it has exerted an inordinate influence, frequently frustrating the fundamental correctional goal of the penalty system. This pound-of-flesh component of penal sanctions may, of course, satisfy the retaliative, often sadistic needs of the nonoffender, but it certainly has not solved the problem of rehabilitating the offender or of protecting society in general.

Yet, penologists are also aware of the strength and pervasiveness of hysterical currents and the futility of seeking to render sound judgment and formulate equitable decisions in the face of them. Periodically, a particular type of offensee.g., kidnaping, sexual misconduct, trafficking in narcotics, etc.-is subjected to intense popular focus, and overly-punitive, vengeful, and discriminatory legislation, completely insensitive to the problem of the individual who has committed the offense, is the characteristic response to the resultant public outcry. Punishment, when thus quantitatively-measured in terms of a given crime, is treated as a specific, and its inflexible rigor soon creates serious problems for the judge, the prosecutor,

*A.B. 1924, Columbia University; M.D. 1928, Long Island Medical College. Director, New Jersey State Diagnostic Center; Diplomate, American Board of Psychiatry; Fellow, American Psychiatric Association. Author [with Albert Ellis], The Psychology of Sex Offenders (1956). Contributor to penological and correctional publications. 
the warden of a penal institution, and the parole official, who long have recognized that there is a difference between the man and his offense.

For every crime committed, however, there seems to be conceived in the public mind a mental image of the offender-the crime and the criminal are fused into one specific concept. Consider kidnaping, for example: The kidnaper is usually pictured as a callous, cruel, calculating individual who commits perhaps the basest of all crimes; and for this, the harshest penalties are meted out-life imprisonment or death. The writer, however, has had occasion to interview at least five persons who were technically charged with kidnaping; and, as will quite clearly appear, even on a cursory examination, none of them even remotely approximated this popular image of a kidnaper.

In the first case, a girl, six years of age, was abducted by a man in his fifties. No force was employed, and no clear design for this offense was ever elicited. The defendant simply induced the girl to accompany him in aimless wanderings through the state of New Jersey and into Philadelphia. When apprehended, he was charged with and finally convicted of kidnaping. Examination revealed that on some six different past occasions, he had been admitted to state hospitals in a psychotic state. He was first diagnosed as manic depressive and later as a schizophrene. Prior to sentencing, he was held for observation on a ward of a mental hospital, where he was described as apathetic, inadequate, aloof, and emotionally-deteriorated. Yet, in the face of all this, he was found to be legally sane. Whether the nature of his offense may have influenced this diagnostic formulation or not is difficult to say. There was, however, no question but that at this point, he was suffering from a chronic schizophrenic process, that he had entertained no intent to harm the victim, and that there was a confused motivation as to the purpose of the whole episode.

In the second case, a man in his thirties allegedly abducted a younger man, twentyone years of age, at the point of a gun, and after traveling some distance out of the state, was alleged to have forced sexual relations upon his victim. He was charged with and convicted of kidnaping. In this particular instance, however, pretrial examinations were made both of the complainant and of the defendant, both in face-to-face interviews and under medication. What ultimately unfolded were the following facts: The complainant had been associated with the defendant in a homosexual relationship for the most part designed for convenience and favors. The defendant was deeply infatuated with his companion, and when he began to suspect a cooling attitude on the part of his love object, sought desperately to win him back through this rather dangerous and senseless action. In fact, when the defendant saw that he was losing the complainant's affection, he was willing to enter into a suicide pact with him, even handing him a gun, saying, "Kill me, for I can't live without you." Under medication, the alleged kidnaper poured forth the violence of his love, observing that the examiner could not understand what true love meant. It was quite obvious that this legally-defined kidnaper was a distraught homosexual whose feelings carried him almost to the point of totally irresponsible 
behavior. In private life, he was a musician, successful and well-respected; and there were no previous signs of aggression or of antisocial attitudes other than his preoccupation with homosexuality, involving, for the most part, individuals over the age of eighteen.

In the third case, a husband, through trickery, removed two of his children from the custody of his wife, with whom they were living. Technically, a charge of kidnaping was considered, but it never was pressed.

In the fourth case, two individuals, inebriated and prankish, abducted one of their companions and not only demanded of him his money, but threatened to kill him. Yet, in the course of this hectic episode, they traveled freely about town, picked up several girlfriends, and afforded the alleged victim every opportunity to escape from their custody. A charge of kidnaping was technically brought against these two offenders who, when interviewed in their sober state, were unable to conceive any intent of ill-doing toward a friend with whom they were on rather close and pleasant terms. They themselves recognized that they were the victims of their own perverted alcoholic fantasy.

In the fifth case, a middle-aged male abducted a six-year-old girl. The girl, although physically unharmed, had been subjected to perverted sexual advances by the defendant. When apprehended, he clearly appeared to be a chronic paranoiac who had developed delusions that this girl was his daughter, and he was so obviously insane that the prosecution consented to his commitment to a hospital for the criminally insane.

It becomes apparent, after reviewing these kidnaping experiences, that there may be great disparity between the individual, the personality, the mental processes, and circumstances surrounding the offense, and the concept entertained by both the public and the law. And what is true of kidnaping is also true of other variations of criminal behavior. Thus, it cannot be overstressed that in addition to the offense, the character and the nature of the offender must also be considered in assessing the penalty, if it is to serve a truly valid and constructive function.

Some progress has been realized in recent years, albeit slowly, through the introduction of the technique of probation, the development of flexibilities in penal dosage in the form of the indefinite and the indeterminate sentence, and juvenile delinquency statutes and youth offender acts-all of which lend considerable latitude to the power of the court. These advances certainly reflect a growing recognition that crime must be regarded only as a surface symptom of an extremely complex dynamic process and that its treatment will best be effected if attack is leveled at the underlying forces which contribute to and produce this antisocial behavior. At the same time, however, these advances have also enhanced the responsibility of the conscientious judge and correspondingly increased his dependence upon other agencies specializing in the study of the offender-e.g., probation officers, the court clinic, the psychopathic ward, the psychiatric and psychological consultants, and the medical clinic. There has developed, accordingly, a most pressing need to establish 
a more effective working relationship between the court and these agencies. Members of the judiciary must place greater reliance upon the interpretations, judgments, and conclusions of clinical services; and the clinician, in turn, must competently recognize the relevant diagnostic elements and translate them into practical form so that they may be used by the court.

\section{II}

\section{The Role of the Clinician}

The impact of psychoanalytic discoveries has had a profound effect upon the concept of crime and the criminal and will ultimately accelerate both acceptance of the thesis that a large group of so-called criminals are really socially and psychologically ill, and the ascendency of the quarantine and treatment rationale of penal sanctions. Such insights into the dynamics of criminal behavior are being developed more rapidly in some areas than in others, but there is, nevertheless, a general disposition at present to place greater emphasis on the psychological and personality factors which enter into the crime equation.

Criminality, like its prototype, delinquency, is a chronic process characterized by a disturbed behavioral reaction, the antisocial impulses of which, it is recognized, were developed to satisfy unmet and rather deep-seated instinctual needs. Criminal behavior is often as much a symptom of psychiatric illness as is a delusion in a paranoid individual or conversion paralysis in an hysterical patient. Diagnostic and exploratory techniques today enable the clinician to uncover many of the derivatives of criminal behavior; crime can be understood in terms of its unconscious motivation. Those who study the mental processes of offenders can readily identify many of the curious mental mechanisms which operate in such cases-i.e., displacement, rationalization, flights from reality, substitution, projection, compulsive behavior, etc. Discussion of these mental processes, of course, is not a function of this paper, but the closer one works with the offender, the more is one impressed that crime is not committed as much by choice as by compulsion, that it is not dominated by a rational process, but is rather inspired and motivated by unconscious pressures.

\section{A. Clinical Techniques}

One of the first and most important clinical techniques involves history-taking. Interpretation of the character of an individual and an analysis of his criminal act become a hazardous procedure without the benefit of his complete life picture. Trained clinical personnel today are able to develop a history in which clinicallysignificant experiences are freely explored, in the light of which, present behavior can more clearly be understood. It is recognized, too, that no interpretation of a given crime is ever final; its significance is rather more fully expanded in the light of future behavior and a more searching reappraisal of past experiences. No diagnosis is ever conclusive; the life story of any offender represents a dynamic process 
and constant flux, and the immediate disturbance can be understood only in the context of the total picture.

For example, a man recently killed a Veterans Administration official in the 'ity of Buffalo, ostensibly because he did not receive a fair hearing and adequate compensation. The prosecutor obtained from the defendant a very logical and rational confession. The examiner in the psychiatric interview, however, recognized the clearly paranoid nature of the act; this particular violence toward the Veterans Administration official expressed, for the defendant, an intense destructive wish against his own father. The history revealed that, ten years before, this same defendant was exonerated of killing another man. Examination of the evidence at that time indicated that the killing had been accidental. Studying the problem from a psychological point of view, however, it was now quite obvious that what appeared to have been an accidental killing was, in fact, another murder. The mental processes which resulted in the earlier "accidental" homicide were the same ones which underlay the later murder. Both were reactions to a fixed delusional idea directed against the defendant's father.

It is important, then, to develop historical data in full. There is always a tendency on the part of the offender to submerge the significance of his act or for the examiner to rationalize it away. A bizarre assaultive episode will appear much more dramatically dangerous to the victim of the assault than to a clinician who is attempting to probe its significance two months later, and if the clinician is not thorough enough, he may be satisfied with the glib explanations of the offender. A sound principle for those who interpret data, therefore, is not to attempt to "second guess" the probation report. Prribation officers, in turn, as well, should be careful not to "second guess" the police reports. This is particularly true in offenses characterized by violence. For this reason, social work and probation departments should be amply expanded, and every effort should be made to staff them with clinically-oriented individuals skilled in eliciting meaningful histories that may serve as reliable guides for later judgment and disposition. Skilled workers can discern those elements in a history which point to medical and psychiatric pathology, and which, accordingly, require further exploration by a medical specialist.

Although pathological criminality stems primarily from a psychosocial disturbance in the individual, not infrequently a physical disorder may be directly or indirectly associated with the criminal act. Certain organic mental states may produce acute criminal acts. Such conditions include general paresis (cerebral syphilis, which is now less common), various alcoholic psychopathies, epilepsy, and deteriorative cerebral states, usually of the senile or sclerotic types. In such types, for example, there is a high frequency of pedophilia. Occasionally, diabetic delirious reactions to an overdosage of insulin raise a legal question. There are obscure neurological conditions, such as encephalitis lethargica, which may produce deviant behavior. There are debilitating conditions, metabolic and dietary, which can also influence behavior. Endocrine disturbances, particularly of the thyroid and the pituitary, are also oc- 
casional contributory factors to behavioral irregularities. Thus, in addition to an adequate history, a careful physical examination is indicated, together with blood studies, x-rays of the heart and lungs, and occasional spinal-fluid analyses. Neurological evaluation of a cursory type is also indicated, with much more complete investigation in those cases in which a neurological condition is suggested.

Electroencephalography (EEG) is widely employed today. It is a technique which is able graphically to register brain-wave activity and different types of dysrhythmias or disturbances in the brain wave, all of interest to the clinician. Many of these are associated with different types of epileptic reaction, which, in turn, may underlie some dissociated behavior or act of aggression. Generally speaking, however, there has been established no special relationship between disturbances of the brain waves and criminal patterns. It is important, therefore, for legal purposes, to be wary of minor deviations in the EEG graphs, lest they be explained as evidence of pathology to exonerate an offender. In any event, pathological electroencephalographic findings should be interpreted only in the light of the total clinical examination.

The psychologist, too, is playing an increasingly more important role. Traditionally, he was confined to the measurement of intelligence. His findings were primarily relevant to those decisions which would establish the mental age of a patient, upon which a commitment to an institution for the mentally defective would be based. In recent years, however, the role of the psychologist has been expanded through the employment of more varied techniques. These are essentially projective techniques and include the Rorschach test and the thematic apperception test. These techniques are valuable, but, again, there is a danger of serious error if they are not used and interpreted in light of the total clinical examination. The projective techniques help to uncover the mental structure and the dynamic process of an individual through the use of standardized stimuli-i.e., particular ink blots in the Rorschach test. Highly disturbed findings on the Rorschach test may alert the psychiatrist to more careful scrutiny of the personality of the defendant. Interestingly enough, in a recent, well-publicized New Jersey case of a Bible-reading youth who strangled a school girl, discussed more fully below, the projective psychological test results obtained years before the crime included specifically a conscious fantasy of strangling a woman. Thus, projective techniques may provide valuable clues and alert examiners to the possible presence of well-hidden pathologic disturbance.

Hypnosis and interviewing with drugs have also proven valuable adjuncts in diagnostic work. Both of these techniques enable clinicians to probe quickly into underlying psychic activity and to uncover emotionally-charged complexes which enable both the offender and the examiner to develop some insight into the meaning of the behavioral symptom. Such techniques are not necessarily a procedure of choice in all cases. For that matter, they do not replace the slower but more effective psychiatric and analytic technique of probing. It must be borne in mind, however, that most offenders are not only verbally-blocked, but their emotional 
feelings are often rigidly covered by defensive attitudes, which causes them not always to react well to the oral interview. It must also be borne in mind that the typical offender does not recognize his criminality as an expression of a neurotic problem or as a twist in his personality. He has developed a pat explanation for what he has done and complacently deludes himself with his capacity to master his problem. The first problem of the diagnostician, then, is to establish a relationship between the act and the deeper emotional content. This achieved, the offender may be in some position to develop rapport with the examiner and generate some interest in his own problem. The amytal interview, which consists of an injection of sodium amytal intravenously, is, in itself, of little value without an analytic interviewing technique. Otherwise, it may have the effect of heavy sedation. This drug makes the offender more accessible; opens up suppressed, inhibited, and even repressed unconscious content; and in some instances, these blocked feelings burst out in very dramatic fashion.

Certain misconceptions should be cleared up at once. First of all, this is not a procedure which establishes the truthfulness or the guilt of the individual. Many personalities, even under medication, not only are able to maintain their secrets, but are also able to confuse the interviewer with falsified data. The efficacy of this medication is that it permits an easier method for the offender to express his fantasies and pent-up feelings. It is of little value in unraveling deliberate deceptions and pathological lying. Evidently, the pathological liar is not far removed from the psychotic, in that he is incapable of clearly testing reality.

Good interviews generally not only yield an underlying content, but provide considerable relief to the offender. Hidden motivations may come to the surface, and a link between the act and the motive may be established. Upon awakening, the offender may or may not have recollections of this insight, and further exploration in nonmedicated interviews is essential. The interview is also helpful in many other ways. For example, it measures the plasticity of the individual. Under medication, some cases dissociate, the type of dissociation frequently seen in alcoholics. Latent delusional material may become freely expressed. In some cases, an acute, but transitory, psychotic episode is observed. This gives the examiner the opportunity to recognize the tenuous margin on which a particular personality is functioning. All in all, an amytal interview is a valuable technique in the sense that it not only attempts to probe into the dynamics, but also enables the examiner to recognize the type of personality, the treatability, the severity of the disorder, and the prognosis. This particular clinical technique is not, however, as widely employed as it should be.

\section{B. Clinical Findings}

An improved methodology in psychiatric work should, in time, dispel the popular notion that psychiatric conclusions are, for the most part, inferential guesses. Knowledge of the offender today is, in fact, greater than ever before and has enabled the clinician to reduce the phenomenology of crime to a few basic categories. 
It is widely recognized that most recidivistic offenders are not psychotic, but rather fall into the category of neurotic individuals with emotional and personality disturbances of a severe type. The layman is able to recognize, at least in part, that the disturbance is deep-seated from the purposeless nature of the offense as well as its self-destructive character. Frequently, there is a meaningful symbolism in the criminal act or a ritualistic repetitious pattern of expression. In some cases, there is a tendency to manifestly aggressive criminal acts; in others, there are no overt aggressive reactions. Many have a special modus operandi that appears to have psychologic significance.

For these reasons, the writer disapproves of dumping all chronic offenders into the psychopathic personality category, which implies either constitutional defects or total lack of conscience. If the individual were to have a total loss of conscience for social responsibilities, he would react in all directions with the same lack of restraint and lack of morality. One finds, however, that many individuals are selectively seeking a specific type of experience and are expressing it with a specific type of crime. As one studies the patterns of offenders, one begins to observe telltale marks that reflect an underlying psychological motive and need. The arsonist, the compulsive shoplifter, the sneak-thief who steals only from bedrooms, and the burglar who can only enter through windows all exhibit psychologic evidence of deeper disturbance.

It becomes quite obvious to students of criminology, therefore, that the basic motivation is not to be found in the rationalized designs of conscious thinking. The offender develops secondary gains from his derelictions and satisfies himself that he has a good reason for what he has done, but deeper exploration soon reveals more powerful and compelling forces which contribute to the criminal episode. While this may not be true of all crimes, it is the case in the vast majority of instances, especially in the case of recidivists. That the criminal act is an external expression of a disguised and deeper motive is one of the most important discoveries that has been made in correctional psychiatry. It was long ago suggested by Freud, Alexander, Healy, and others, but today, with better history-taking techniques, analytical methods, hypnosis, use of sodium amytal, and projective techniques, it has been possible to confirm this finding.

Since repetitious criminal acts are so deep-seated in origin, one school of thought believes that the roots are constitutional. Study of the histories in many hundreds of these cases, however, reliably demonstrates that the pathological offender is involved in an acquired reaction, usually stemming from the earliest relationships with members of his family. Feelings of rejection, basic insecurities, inconsistencies in training, all types of inferiorities, traumatic experiences, overprotective parental attitudes, etc., are all part of the general group of etiologic factors that seem to underlie the delinquent reaction. The motivation of the reaction would seem to indicate that it is intended to satisfy basic needs which cannot be openly and constructively expressed. In a number of cases, the offense represents an unconscious expression 
of aggression and hostility which may be well-masked; in others, the offense represents a circuitous seeking of ego status; and in still others, it represents a seeking of an opportunity for greater dependency. The self-punitive mechanism, too, is frequently a patent factor in the mental functioning of many offenders.

An individual can commit offenses, of course, without being classified as pathological. Man is by no means perfect, nor has he sublimated all of his antisocial impulses. Primitive infantile residuals exist in even highly successful and adjusted individuals. Such persons, more commonly the young than the old, constantly test the environment and reality and guide their behavior by the sanctions that deter them. These individuals are adaptive, attuning their conduct to the framework of rules. For them, unlike the pathological offender, penal laws have a deterrent effect. There are, however, environmental stresses and pressures or special sets of circumstances which lead to the breakdown of control and result in crime. But the crime is predominantly the result of external forces, for there is little within the individual in terms of internal pressures and compulsions which has contributed to the offense. Such individuals seem to have an adequate sense of values; they have no deep antisocial drives, and they have a capacity to develop insight into their wrong-doing and are adaptive enough to profit from the experience. In short, their prognosis is usually good, and, accordingly, they probably would qualify for probationary handling. Yet, the peculiar paradox exists that these individuals are frequently punished because they should have known better.

The concept of the psychopathic personality, which defines another basic clinical category of offenders, is usually ascribed to that type of repetitive offender who continues his antisocial pattern, disregarding threats of punishment. This type of personality, with newer methods of investigation, yields to a more dynamic approach in which the clinician attempts to understand the psychologic purpose of the crime and the emotional needs it attempts to satisfy. Psychological exploration produces a great deal of knowledge concerning the complex dynamic reactions found in such individuals. Unconscious motivations are uncovered, together with the emotional forces which pressure them. In such individuals, the crime is seen to be based on internal unconscious drives, rather than external situations. Many mental mechanisms operate in the psychic functions of psychopathy. Analysis may reveal that a stealing episode represents a substitute satisfaction for the need to be emancipated or may serve as an outlet for deep-rooted resentments. An aggressive guntoter may assert his masculine needs and compensate for his feelings of inferiority through antisocial activity, although he may not be at all aware of these stimuli nor of his passive feminine inclinations. The element of compulsion is not only observable, but in some instances measurable.

These internal and intense needs to seek satisfaction in such a compelling way are not always recognized as compulsions, as attempts by psychopathic repetitive individuals to express a psychological design based on earlier and unhappy experiences. When the true picture is uncovered, however, and clear knowledge of the basic 
mental process is obtained, prognostic evaluations are possible. It is with the "psychopathic" criminal that the greatest work must be done to remedy the ineffectiveness of penal treatment. It is unfortunate that the traditional and common point of view toward this group is that they are incurable and unrehabilitatable types.

Careful diagnostic studies of these psychopathic reactions when rendered to the court, however, may not have practical value in terms of disposition. This is particularly true if there are no agencies at the disposal of the court which adequately render service of a specialized-treatment type. There is usually a tendency to incarcerate, except in those few cases where the defendant does not offer too great a threat or where he is able to develop a satisfactory treatment plan through his own resources. But whatever the results of psychotherapy may be at the present time, theoretical postulates with reference to emotionally-disturbed offenders should offer greater hope of modifying the neurotic reaction through some planned treatment, rather than through simple hibernation in penal institutions or through a supervised plan within a crowded probation system unimplemented with clinical help. Better knowledge of the neurotic process of the recidivist should also increase efforts toward earlier detection, preferably in the predelinquent stage of development, and greater resources should be developed in our correctional schools and in our public schools.

A third basic clinical category of offenders, not as readily understandable, shows. signs of personality-splitting. These individuals lack the inner coherence observed in neurotic offenders. There is greater evidence of internal rift and disintegration. Their mental pathology shows much more marked evidence of disorder. Dissociative conditions are common. Delusional reactions, either manifest or latent, may be detected. Their emotional responses are more inappropriate. These cases fall under the general heading of the schizophrenia.

There are many variations of this basic disturbed typology. Dementia is not always observed on the surface; yet a psychotic process exists. Generally speaking, the psychotic types-latent, overt, or in remission-are more unpredictable. The genesis of their psychological development is not always too clear. There is usually a greater danger of highly pathological explosions of aggression. The surface behavior has a greater element of bizarreness and senselessness, and is even less realistic than the behavior commonly seen in psychopathic types. These findings are rather common, for example, in murderers and in individuals who have committed violent assaults. Unless the clinical examination is done competently and carefully, however, such types may be erroneously classified as psychopathic personalities. In other than homicide cases, they are usually treated as correctional cases, and little or nothing is done to help them from a medical point of view.

These cases are truly in no-man's land-for, on the one hand, they are sufficiently integrated to pass off as ordinary criminals; and yet, on the other, they are actually sufficiently disorganized to be treated with hospital techniques. From this group, within our prisons, come those individuals who characteristically develop acute psychotic episodes which frequently necessitate short periods of hospital care. Among 
the patterns found in this borderline psychotic group are included the following:

I. Simple schizophrenic reaction with impoverished emotional makeup, lack of goal in life, inertia toward responsibilities, but no obvious dementia.

2. More obvious schizophrenic personality who has had some previous acute episode but now is apparently stabilized in remission.

3. Acute dissociated homicidal reactions frequently seen in schizoid or schizophrenic teen-agers and young adults. This is obviously a psychotic explosion where the ego is ruptured, following which there seems to be an absence of acute psychotic symptoms. The aggressive act seems to have been completely split off from the mental process. There is profound narcissism, little or no sense of guilt, and a history unlike that of the pyschopathic-neurotic offender, in that there may have been no apparent deprivational experiences in the home. Such cases are commonly given long sentences. They seem to adjust well in institutions and do not seem to regress too much.

4. The whole family of paranoia and paranoid states. These cases have particularly interesting legal implications, in that the individuals are prone to litigation and legal entanglements, often serving as their own attorneys or running from one attorney to another. Many of the mechanisms of the paranoid group have revealed themselves through explosive assaultive reactions. As one studies the psychologic basis for the assault, one recognizes that there is a delusional misinterpretation of the environment. The explanation for the offense, however, is placed at a superficial level. The true nature of the pathology is important, as these individuals are particularly dangerous and should be quickly recognized so as to afford maximum protection to society. The delusional process is subtle, but it can be uncovered. Alcohol frequently serves as a release mechanism in such cases.

The paranoia group, on the other hand, is not prone to assault. These individuals express themselves through accusation, notoriety, and litigation. They suffer from delusional ideas and project their own conflicts upon others. Their usual projective accusations include insanity, poison, and perversion. They make false accusations with so much assurance and seeming proof that the victim frequently suffers an injustice. This is a chronic state subject to periods of exacerbation. In as much as these individuals tend to document most of their observations and many of their delusional needs are thus masked, they have a tendency to trap their own attorneys, who strongly identify themselves with the case and become deeply entangled.

Such cases do not offer a ready solution. In the first place, these individuals reject any therapeutic plan, they do not seek a solution; all they are trying to do is to prove something. Further, they involve other people in their systematized litigation. Altogether, they present a rather difficult problem. The present treatment is correctional. They are considered criminal rather than sick people. This further feeds their problem and postpones whatever constructive measures could be employed in a hospital setting. It is recognized that when offenses stem out of a delusion matrix, no matter how latent the process may be, the offenders are func- 
tioning psychotically. Such diagnostic refinements are of little practical use in the sentencing procedures, however, since there is no sentencing procedure that takes into account the subtle individual pathological variations observed by the clinician.

\section{Clinical Contributions}

Psychiatry of the offender has become a specialty within a specialty. Those who deal specifically with offenders are less prone to hold to a static view of personalities. They study the antisocial personality as one that has largely been acquired. They recognize that in the causal emotional and psychological problem, there is a particular type of development, and symptom formation results largely to express the solution of individual conflicts. This is a positive and constructive point of view. It does not consign all pathological offenders forever to the segregation cell. It recognizes that there is need for a highly individualized approach in terms of understanding and treatment.

While these psychiatric advances are substantial and should serve as forerunners of more competent and effective diagnostic techniques and preventive programs, clinicians are still somewhat discouraged at the lack of a complete solution related to the problem of treating the pathological offender. A high degree of refractoriness to treatment exists even where the psychological and emotional genesis seems clear and where insight seems to have developed. But notwithstanding the tremendous amount of work yet to be done with regard to the offender, it is safe, to say that clinical knowledge has developed far beyond the court's ability to deal with it on an individualized basis and, in the passing of sentence, to do full justice to what is known of the offender, in terms of both causes and his needs for readjustment.

It must, however, be admitted that not all the advances of psychopathology are readily applicable, and in some instances, many of the clinical findings have a theoretical rather than a practical utility. A simple illustration of this is to be found in work done on preparole cases for boards of parole. In too many instances, the issue before a parole board is a limited one: whether to release an inmate or detain him. Ultrarefinements in clinical findings, while psychologically interesting and academically important, have a limited application when the only question that the parole commissioner asks is: "Is he safe to be released?" But this overaccommodation on the part of clinical services to the limitations necessitated by fixed penal processes need not invalidate the useful application of psychiatric knowledge where there are many practical ways in which it can be employed by the court. The theoretical advances, moreover, once well-established, will undoubtedly have greater influence on the penology of the future. They may, for example, lead to a further acceptance of the indeterminate sentence on a more universal basis and the expanding of legislation dealing with pathological offenders-both of which would not in any way lessen the social safeguards and, at the same time, would increase the prospects of rehabilitation. 
What are some of the observations and experiences which the clinician may usefully contribute? First, essential findings must be developed dealing with the recognition of psychosis. It is obvious that the patent psychotic reaction causes no great difficulty. Where florid delusional and hallucinatory experiences are exhibited, together with obvious disintegrating and deteriorating reactions, they are very readily perceived. But where the psychotic process is either in latent form or not fullblown, the greatest difficulties have been encountered.

In practice, the strict application of the M'Naghten rules would hold the defendant fully accountable, even where there is evidence that the criminal act itself is either an acute or a chronic expression of a psychotic process. Frequently, too, an end product of a latent delusional idea is not fully-recognized and is not systematized into other delusional ideas. This borderline group offers no end of problems. It is quite obvious to any practical clinician that such a defendant, although perhaps not within the rigid definition of insanity, is not medically responsible. The clinician also recognizes that latent delusional and paranoid elements have a compelling force about them, and even though the defendant intellectually perceives the physical nature of his act, responsibility is certainly mitigated by his pathologicallytwisted mental process. There happily seems to be an increasing, although by no means universal, disposition on the part of prosecutors to take into account the senseless nature of the crime and its obvious psychotic implications and thus settle for compromised pleas. This is certainly a more sensible approach, for it affords the public adequate protection.

A recent murder of a school girl in New Jersey, mentioned above, caused tremendous furor both in the immediate community and elsewhere, owing largely to sensational press coverage. This homicidal act was committed by an eighteen-yearold Bible-reading youth who had been examined at the Diagnostic Center in Menlo Park five years earlier. During this earlier commitment to the institution, some bizarre elements of his behavior were observed, including a hostility toward his mother which was expressed only in symbolic form. He would almost compulsively cut her dresses to shreds, and occasionally he committed a vandalistic act. It was clear that this basic aggression toward his mother was later displaced onto the unfortunate victim. Clinically, all the elements of a schizophrenic reaction were evident: the senseless nature of the act, the lack of affect, the acute psychotic eruption which usually occurs in such incidents. Yet, there was little doubt that if the case came to trial the jury would have been compelled to find this youth 'fully responsible. The wisdom of the prosecutor in recognizing that he was dealing with a latent psychotic is commendable; he found a practical solution by not demanding the death penalty, but rather a life sentence, thus doing justice to the evidence of a mitigating psychiatric disorder and the demands of community safety. It is commendable, too, that other prosecutors are adopting a similar practical approach and are not being unduly pressured by popular opinion to demand maximum penalties. 
There are many variations of borderline psychotics-some have already been described. With respect to them, all the clinician can do is to spell out the essential symptomatology which constitutes the medical insanity. There is no way to translate such psychopathologic states into legal equivalents. A schizophrenic, who is known to be a mentally-ill person, may, on the basis of present procedures, therefore, be legally sane. Pending changes in procedure which will recognize the psychotic state apart from the legal issue of insanity, however, clinical services can assist the court in recognizing and describing the so-called psychotic reactions. Although the borderline psychotic must, at the present time, be treated within the framework of the penal process, the fact of impaired responsibility certainly can be considered by the court. In this connection, it is essential that all perpetrators of serious crimes be psychiatrically screened prior to sentencing and in some cases prior to trial. It may also be entirely possible for clinicians to develop a procedure for dealing more effectively with borderline psychotics who are committed under a correctional sentence. Here, the greatest emphasis of course, must be on further study of the psychiatric condition and ways and means of modifying it through therapy.

More generally, with respect to all offenders, clinicians can provide the court with relevant data which may include any or all of the following points:

I. A clinical evaluation of the seriousness of the offense.

2. The psychological matrix from which this offense arose and the underlying psychological significance of the act.

3. The diagnostic category into which the defendant falls.

4. The chronicity of the process, with evidence of repetitive, compulsive elements, if any.

5. The insight the defendant has obtained into the true nature of his crime, if any, including the amount of guilt, sense of remorse, etc.

6. The motivations and responsiveness he has for a treatment plan, should one be necessary-i.e., how plastic is an individual to remedial efforts, both general and specific?

7. The degree of hazard he poses for others in the community; the prospects of a dangerous episode repeating itself.

8. The over-all prognosis.

9. Recommendation:

a. quarantine (institutionalization);

b. probation; or

c. any special ancillary measures which may specifically lessen or remove causal factors toward crime or contribute to reducing stresses which lead to crime, such as referral to Alcoholics Anonymous, medical treatment, or psychotherapy, either individual or group.

Such a rough framework of data should be useful to the court. It may also have some value to the agencies which may be called upon to supervise the defendant, reither in the institution or on probation. In preparing such reports for the court, it 
is quite essential that the psychiatric data be expressed in a simple language, and this need not invalidate the scientific findings. Dogmatism should be avoided, and speculation should be clearly described as such. One must guard against the danger of becoming overly-exonerative in attitude. It is important for the clinician to avoid injecting his own personal philosophy into his reports. A psychiatrist who happens personally to feel that prisons do harm to a defendant may be reluctant to recommend incarceration. The judge may, consequently, classify this "expert" as one who would exonerate all offenders. Another psychiatrist, impressed with the psychopathology of a given crime, may too enthusiastically prescribe ambulatory care, without sufficiently weighing the seriousness of the offense or the threat of recurrence. In short, an adequate clinical report to the court should have the virtues of simplicity, validity, and adaptiveness.

\section{III}

\section{IMPLEMENTATION}

The major problem, as regards psychiatry and the courts, is that, notwithstanding the broad discretion that any court may enjoy, the judge is necessarily quite limited when he exercises his sentencing function. The treatment process is not fully considered unless the defendant is obviously insane and commitment results. There are insufficient resources available to the court to carry through recommendations and insufficient personnel, both within correctional institutions and outside in the community, who are able to utilize the increasing knowledge and insight that has been gained from psychiatry. Owing to strong pressures of a retributive and deterrent type, together with marked skepticism towards the specific efficacy of psychotherapy and psychiatric findings in general, decisions of the court tend to be made in the direction of incarceration, at times, perhaps, when more effective and constructive solutions could be found. The penal concept requires some modification to profit from the added knowledge which clinical methods create.

The sexual psychopath statute in the state of New Jersey creates a procedure which represents perhaps a true milestone in correctional philosophy and which may serve as a forerunner of change in the treatment of other forms of crime. Through special legislation, where the sex offense is found to be compulsively repetitive and to involve minors, a given individual may be treated in a hospital rather than in a penal institution. The maximum sentence remains the same, but its duration is indeterminate, and the major objective is to improve the capacity of the offender to adjust.

The public apparently is willing to accept special legislation regarding sex offenders, but it is not yet prepared to extend these concepts to other cases. Yet, the need there is as great. For example, a young married man, a college graduate, engaged in a series of breaking and enterings. Examination at the clinic, through hypnotic and drug techniques, surprisingly enough, indicated that these offenses were not only compulsive in nature, but were related to a sexual fetish associated 
with women's gloves. For the first time in his life, the subject revealed insight and recognized the compulsion and the true motivation. Reports to one court of these findings brought support for probation which was to be implemented by psychotherapy. A month later, however, while analysis of the diagnostic procedure was still continuing, the offender appeared in another jurisdiction on charges arising out of offenses of the same series. And this latter court, weighing carefully all of the factors involved, decided against ambulatory treatment and committed him to an institution. Perhaps the seriousness of the offense and other factors, including extensive publicity, weighed against release, as well as the fact that the court could not be given absolute assurance of recovery through a specific therapeutic method.

This epitomizes a problem faced so frequently with offenders who have strong neurotic and compulsive crime patterns involving not only sexual misconduct or sex-related offenses, but other crimes of acquisition, arson, violence, etc. Such cases are predominantly psychiatric in nature, and one cannot be certain as to the effects of therapy. The writer feels that great advances could be made if more experimental work were attempted. Treatment cannot always be carried out in the vacuum of a penal institution and may only be successful when conducted within the community. This may involve a certain element of risk, but this, in turn, is neutralized by more effective supervision and better hopes of more complete readjustment. Opportunities to develop facilities for such cases are necessary if the sentencing procedure is to become more meaningful. Not only would such facilities help to implement probationary work, but they would certainly invite earlier releases for cases that would respond to a treatment plan.

More public education is required to establish faith in the judgments of our courts and the agencies dealing with the offender. In this, the profound influence of the press and public opinion cannot be underestimated. At times, in a climate of intense emotional upheaval, it would seem that those entrusted with the disposition and care of offenders are pilloried. The writer has seen parole boards actually panicked by the pressure of notoriety and press criticism. It is important, therefore, to develop in the public a confidence that those agencies dealing with the offender are trustworthy and carry on their work with integrity. In this process, no judgment is ever absolute, and to varying degrees, risks are involved either in committing or releasing offenders to and from our institutions. In fact, to take action which does not involve risk or an occasional mistake only invites an agency to bury its mistakes, without regard to justice and the necessary redemption of the individual.

Probation is a recipe which permits an offender to remain in the community rather than to be placed in confinement. There are no clear-cut criteria or yardsticks which permit an objective judgment on the indication for probation, and many of the criteria are contradictory. For example, a man may have committed a serious crime, but because of a good attitude, a high degree of insight, and remorse, he would make a good probationary risk. This may create a profound conflict in the mind of a jurist. It is for this reason that it is impossible to set up an absolute set 
of rules to govern probation. Out of a group of extremely complex and sometimes subjective factors, a judgment is developed, and the line may be very thin in decisions to incarcerate or to release on probation. This problem sometimes is further compounded by the existence of special psychiatric factors. The agency of probation would, accordingly, prove more valuable if, in its operation, it were implemented by some form of treatment resources which would permit experimental ambulatory treatment for offenders, especially those who seem to have a responsiveness to some form of therapy and those who do not present too serious a hazard to the community. With such expansion of probation facilities, moreover, there would likely be a more emphatic reliance by the court upon diagnostic evaluation and findings which could then be translated into more practical terms.

It is important, however, to stress the personal attitude of the judge, for his specific philosophy will sometimes be a chief determinant, especially in borderline cases. There are many cases which present a dilemma to the court, in that whatever the judgment, there will be collision with some of the criteria of probation. Recently, for example, a middle-aged man was charged with incest, a crime that seems to be abhorrent to most people. The victim was thirteen years of age. Yet, the examination of the offender revealed a man of unusual probity and stability. He was the step-father. His life pattern was characterized by industry, honesty, and a specific tendency to conform. The stepchild had developed negative attitudes toward her own mother and had become strongly attached to the stepfather. There were also some indications of seductive behavior on the part of the child. In any event, this highly-inhibited, repressed, but conforming individual gradually indulged in some sex play which ultimately led to a full-blown sexual relationship. From a clinical point of view, it was felt that there had been a loss of control, but there were no severe pathologic findings which would indicate the likelihood of a recurrence of this behavior. His relationship with his wife was good; she was standing by, somewhat grief-stricken by the whole experience. The child had been removed from the home. From a practical point of view, the psychiatrist could not see how imprisonment would help. The psychiatric attitude took into account the high degree of remorse and the minimal risk involved in probation, the financial condition of the home, and the adaptiveness and the willingness of the offender to seek treatment, although this was not particularly necessary. On the other hand, there was the crime and the youth of the victim. It was impossible absolutely to weigh one factor against the other. Psychiatrists recommended probation in terms of the entire picture. The court, on the other hand, decided on commitment. It seemed, in this particular case, that the strong rehabilitative possibilities and the other positive factors described did not overbalance the powerful need to punish.

In as much as a large range of offenders exhibit potentialities that rather seriously threaten others, efforts are being made, through a new code, to develop a supermaximum sentence to be exacted of dangerous offenders. In theory, this is both feasible and desirable; in practice, however, the problem becomes vastly complicated. 
There is doubt that any legal instrument exists that can satisfy all conditions. Clinical criteria that point to the possibility of further dangerous behavior cannot always be dogmatically defined. Only in clearly psychotic conditions, with a history of previous psychotically-aggressive episodes, can medical opinion find common agreement; otherwise, conclusions may be based on criteria which become contestable in a court of law. An offender who is placed in further jeopardy on the basis of a clinical opinion may thus be called not only to defend his guilt, but to defend himself against the clinical findings. A supermaximum sentence for dangerous offenders in application, moreover, could readily degenerate again into the old habitual-offender acts, with the number and kind of previous convictions serving as a basis for this special sentence, rather than proven clinical evidence.

This does not minimize the importance of clinical findings; but research and experience have not brought us yet to the point where it can clearly and absolutely be indicated that certain classes of individuals will inevitably commit certain crimes. Such findings, however, would have greater validity within the punishment framework of a given case. If an extended sentence is to be considered as part of the new code, adequate diagnostic facilities should be established to screen cases in which it is assertedly applicable. Furthermore, an extended maximum sentence should not preclude opportunities for release at an early period for the offender, and certainly greater efforts should be made within our correctional institutions to provide such individuals with specialized medical and psychologic care.

IV

\section{ConcLusion}

Where do we stand today? It is recognized that penal treatment need not rest on a rigid set of formulae, periodically modified on popular demand. A reasonable set of penalties will have a deterrent effect, and more stringent penalties will not necessarily be reflected in a commensurately higher degree of conformity. The process which fails to react to moderate sanction may be altogether insensitive to excessive penalties as well. Paradoxically, those who require sanctions the most are the very ones who are least influenced by them. So, we are moving toward an individualized penal treatment, within a loose framework of more defined penal codes. We are moving toward a wider range of indeterminate sentences, within the limits of which one may release from confinement those who warrant release earlier and retain those who are unsafe to be in the community.

Harsh fixed sentences do not work out well. One recalls the period of the Baumes Law in New York. The prisons were jammed with long-term offenders; and whether or not they had potentialities for adjustment, they were precluded from release. There were young men in their twenties whose aggressive behavior now had been tempered with age and biological maturity, who were still confined and compelled to serve out these long sentences. Bitterness, hostility, and festering hate increased. Parole boards were helpless in the face of the sentences that were meted 
out. The condition eventually and inevitably led to explosive results and prison riots. Investigations followed, and revisions of law took place.

From the penal point of view, we are moving toward the recognition of three or four basic categories of offenders, reflecting the seriousness of the offense. There is a tendency to reduce harsh inflexible sentences and to develop legislation creating extended sentences for especially dangerous individuals. If the court and the public are going to surrender the heavier sentences in certain cases, they must have this or some similar safeguard to take its place. The concept of the extended sentence, while laudable, however, may encounter great difficulties at the practical and legal levels. It must be clearly based on diagnostic findings, for if it is not, it may degenerate into habitual-criminal legislation once again.

We must recognize that diagnostic methods at this moment, while improving and helpful, cannot yet become converted into legal equivalents. Yet, it is essential that we develop a mechanism that would afford society full protection in those cases that are dangerous. Perhaps in creating a special extended sentence, we must not only incorporate the protective elements of an extended maximum, but also emphasize its indeterminate aspect and its treatment implications. Under such conditions, perhaps a supermaximum sentence may become less objectionable to the defense. We must recognize that there is no system of penalties that can assure the ideal justice for all. All we can ask is that it be more equitable than any other preceding system.

The treatment of the pathological, repetitive, and compulsive offender may ultimately be considered in special legislation. Such laws might be modeled on the sexual psychopath law of the state of New Jersey-an indeterminate sentence, under which treatment rather than custody is emphasized, while the maximum sentence remains the same. The main problem must be recognized to be predominantly psychiatric in nature, and the murder trial and the battle of experts-the show that the public enjoys-may have to be sacrificed for a more objective, scientific penology. Perhaps harsh, repressive penal philosophy will yield to one that is enlightened. The agencies of the clinic, probation, parole, and scientific sentencing may yet come actually to fulfill the objectives for which they were designed. They may emphasize the man rather than the formula, social protection rather than social retribution. They may emphasize early release and treatment when compatible with public safety. They will search for maximum justice without claim to perfection. 